\title{
Estudo do descarte residencial de medicamentos vencidos na região de Paulínia (SP), Brasil
}

\author{
Study of residential expired medicines disposal in Paulínia (SP) area, Brazil \\ Gláucia Maria Ferreira Pinto', Kelly Regina da Silva², \\ Rosana de Fátima Altheman Bueno Pereira², Sara Issa Sampaio ${ }^{2}$
}

\begin{abstract}
RESUMO
O avanço da ciência na área da saúde proporcionou um aumento na fabricação de medicamentos, que na maioria das vezes, depois de vencidos, são descartados de maneira inadequada, geralmente no lixo comum. Estes resíduos, quando em contato com o solo e a água, podem causar contaminação, que mesmo em uma rede de tratamento de esgoto não é eliminada completamente. O objetivo do estudo foi conhecer a destinação dada aos medicamentos vencidos de residências. Para isso foi feita uma pesquisa comportamental com alunos de cursos de graduação e técnicos situados na região de Paulínia, em São Paulo. Adicionalmente, levantou-se o grau de conhecimento do público-alvo sobre a existência de locais apropriados para o descarte de medicamentos e de campanhas públicas de esclarecimento. Os resultados indicam que a maioria das pessoas descarta inadequadamente por falta de esclarecimento sobre o assunto. Palavras-chave: contaminação ambiental; descarte de medicamentos; resíduos sólidos farmacêuticos.
\end{abstract}

\begin{abstract}
The advancement of science health care provided an increase in drug manufacturing, which in most cases, after the losers, are discarded improperly, usually in the trash. These residues, when in contact with the soil and water, can cause contamination, that even in a network of sewage treatment are not completely eliminated. The aim was to study the disposal given to expired medicines used at homes. For this was made a behavioral research with undergraduate and technicians students located in region of Paulínia, in Sao Paulo. Additionally, were collected information about the degree of knowledge of target on the existence of suitable sites for disposal of medicines and public awareness programs. The results indicate that most people discard medicines improperly by lack of information on the subject.
\end{abstract}

Keywords: environmental pollution; drugs disposal; solid waste pharmaceutical.

\section{INTRODUÇÃO}

O avanço da ciência na área da saúde e as pesquisas de novos tratamentos trouxeram benefícios incontestáveis à população, o que também proporcionou um aumento considerável na fabricação de novas fórmulas e na quantidade de medicamentos disponíveis para comercialização e consumo.

A cultura brasileira de automedicação e a fácil aquisição desses produtos acabaram por gerar nas residências brasileiras um acúmulo de medicamentos. As "farmacinhas caseiras", como são conhecidas, geralmente contêm algumas fórmulas reservadas às emergências (antigripal, analgésicos, antitérmicos), vendidas sem receita médica, mas também é muito comum conter sobras de medicamentos controlados (antibióticos, entre outros) que provavelmente não mais serão utilizados, mas que ficam guardados até a expiração da sua data de validade (BUENO; WEBER; OLIVEIRA, 2009).
Deve-se atentar para a data de validade dos medicamentos reservados em casa, pois é o indicativo da perda total ou parcial da eficiência dos princípios ativos contidos naquele produto.

A partir deste momento começam os problemas: onde e de que forma descartá-los?

Medicamentos são considerados resíduos químicos pela Agência Nacional de Vigilância Sanitária (ANVISA), ressalta Wanda Maria Risso Günther, professora da FSP (Faculdade de Saúde Pública) (MORAIS, 2011). À medida que são dispostos a céu aberto, os medicamentos são agora parte do lixo, disseminam doenças por meio de vetores que se multiplicam nesses locais ou que fazem desses resíduos fonte de alimentação (RODRIGUES, 2009).

Os fármacos não são removidos pelos tratamentos de água convencionais, já que suas propriedades químicas são persistentes, têm alto $\square$

'Bacharel em Química, Doutora em Ciências, Coordenadora do Curso de Gestão Ambiental e Professora da Faculdade de Paulínia (FACP) - Paulínia (SP), Brasil. ${ }^{2}$ Tecnóloga em Gestão Ambiental - Paulínia (SP), Brasil.

Endereço para correspondência: Gláucia Maria Ferreira Pinto - FACP - Rua Nelson Prodócimo, 495 - Jardim Bela Vista - 13140-000 - Paulínia (SP), Brasil - E-mail: gm.ferreirapinto@gmail.com

Recebido: 17/07/12 - Aceito: 22/11/13 - Reg. ABES: 472 
potencial para bioacumulação e baixa biodegradabilidade. Por isso, não há método sanitário que os retire completamente da água, mesmo em uma rede de tratamento de esgoto (CRESTANA; SILVA, 2011).

A bioacumulação pode ocorrer de forma direta ou indireta, sendo que na forma direta as substâncias químicas acumulam-se pelo contato direto com o ambiente contaminado através de via oral, percutânea e respiratória. Já na indireta os produtos químicos acumulam-se nos organismos vivos a partir da cadeia alimentar (GUIMARÃES, 1987).

$\mathrm{O}$ descarte inadequado de medicamentos, principalmente no lixo comum ou na rede de esgoto, pode contaminar o solo, as águas superficiais, como em rios, lagos e oceanos e águas subterrâneas, nos lençóis freáticos. Essas substâncias químicas, quando expostas a condições adversas de umidade, temperatura e luz podem transformar-se em substâncias tóxicas e afetar o equilíbrio do meio ambiente, alterando ciclos biogeoquímicos, interferindo nas teias e cadeias alimentares. Podem-se citar, como exemplos, os antibióticos que, quando descartados inadequadamente, favorecem o surgimento de bactérias resistentes, e os hormônios utilizados para reposição ou presentes em anticoncepcionais que afetam o sistema reprodutivo de organismos aquáticos, como, por exemplo, a feminização de peixes machos (EICKHOFF; HEINECK; SEIXAS, 2009).

Nem toda contaminação é proveniente do descarte inadequado, alguns componentes são excretados pela urina ou pelas fezes. Entre $50 \%$ e $90 \%$ de uma dosagem são excretados sem sofrer alterações e persistem no ambiente (UEDA et al., 2009).

Outro aspecto a ser abordado é que, na maioria das cidades brasileiras, o lixo ainda é despejado em lixões, possibilitando que principalmente os catadores consumam inapropriadamente os medicamentos ou os descartem diretamente no solo, para o reaproveitamento das embalagens. O consumo indevido de medicamentos, principalmente os de data de validade expirada, pode levar ao surgimento de reações adversas graves, intoxicações, entre outros problemas, comprometendo decisivamente a saúde e a qualidade de vida dos usuários (ANVISA, 2011).

Em Paulínia, a empresa Estre Ambiental recolhe, transporta e realiza a gestão integrada dos resíduos recolhidos. A segregação é realizada em aterro controlado e existe inclusive uma planta de tratamento de resíduos classe I (resíduos sólidos perigosos) e hospitalar, porém o tratamento só ocorre com o resíduo encaminhado separado e identificado. Assim, medicamentos recebidos com o resíduo doméstico ou comercial não são tratados (classes IIA e IIB), mas sim direcionados ao aterro, sendo que a quantidade recebida encontra-se ao redor de 40 mil toneladas de resíduo por dia. Por esse fato, reforça-se a necessidade de conscientizar a população quanto ao destino correto dos medicamentos fora de uso.

A falta de venda fracionada também contribui de forma bastante significativa para a geração dessa quantidade de medicamentos vencidos. Está em tramitação na Câmara dos Deputados o Projeto de
Lei $n^{\circ}$ 396/11, que dispõe sobre o fracionamento de medicamentos. A legislação atual, Decreto n 74.170/74 que regulamenta a Lei n 5991/73, permite o fracionamento sem torná-lo obrigatório. Existe uma lista, editada pela ANVISA, de 800 medicamentos que podem ser fracionados (LIBRELON, 2011).

É relevante citar que a distribuição de amostras grátis por parte dos laboratórios, através de seus representantes, sem que se tenha certeza de seu real uso acaba por aumentar a quantidade de medicamentos vencidos.

A ANVISA estima que cerca de 30 mil toneladas de remédios são jogadas fora pelos consumidores a cada ano no Brasil (CARNEIRO, 2011).

O desconhecimento da população e a falta de orientação por parte dos poderes públicos ocasionados pela escassez de campanhas explicativas são a principal causa desse descarte inadequado.

A Lei $\mathrm{n}^{\circ}$ 12.305, de 02 de agosto de 2010, que institui a Política Nacional de Resíduos Sólidos (PNRS), estabelece que o setor produtivo, os usuários e o poder público têm responsabilidade compartilhada na destinação correta dada aos produtos e aos bens de consumo, ao final de sua vida útil. De acordo com a PNRS, o país estabelece regras para lidar com os resíduos que puderem ser reciclados; e os rejeitos, que antes poluíam o meio ambiente, como os medicamentos, passarão a ser tratados de forma ambientalmente adequada (BRASIL, 2010).

Pesquisas em sites oficiais do governo levam apenas a resoluções que tratam em sua maioria das classificações dos resíduos gerados nos Serviços de Saúde (como acondicioná-los, transportá-los e de suas destinações finais), como a RDC ${ }^{\circ}$ 306, de 7 de dezembro de 2004, da ANVISA, que dispõe sobre o regulamento técnico para o gerenciamento de resíduos de serviços de saúde, e a Resolução n 358, de 29 de abril de 2005, do Ministério do Meio Ambiente, que dispõe sobre o tratamento e a disposição final dos resíduos dos serviços de saúde. O descarte de medicamentos em desuso ou vencidos de residências não possui ainda legislação específica (BRASIL, 2004; BRASIL, 2005).

Está em tramitação no Congresso Nacional o Projeto de Lei (PL) $n^{\circ}$ 595/11 que acrescenta o artigo $6^{\circ}$ à Lei no 5991/73, que dispõe sobre o controle sanitário do comércio de drogas, medicamentos, insumos farmacêuticos e correlatos. Este PL visa obrigar farmácias, drogarias e postos de saúde a receberem da população medicamentos vencidos ou a vencer e encaminhá-los aos laboratórios da indústria farmacêutica, que por sua vez devem destiná-los de maneira adequada e sustentável para o meio ambiente (BRASIL, 2011).

Este trabalho tem como objetivo realizar um estudo pontual do comportamento das pessoas com relação ao descarte de medicamentos vencidos e o grau de conhecimento dos entrevistados sobre a existência de locais de recebimento destes resíduos e de campanhas públicas de esclarecimento.

Embora existam diversas possibilidades de descarte que podem agredir o meio ambiente, no presente estudo consideraram-se somente os efetuados nas residências dos entrevistados. 


\section{METODOLOGIA}

A etapa inicial do presente estudo priorizou a pesquisa sobre a legislação brasileira pertinente e busca de informações sobre campanhas educativas já existentes nos sites oficiais do Ministério da Saúde e ANVISA, que serviram de base para o desenvolvimento do trabalho apresentado.

Em seguida, foi elaborado um formulário contendo os principais pontos a serem considerados no estudo, procurando identificar nichos comportamentais. As questões foram baseadas nas experiências pessoais das autoras e nas informações encontradas durante as pesquisas com relação à "farmácia caseira” e os principais tipos de medicamentos manipulados.

A coleta de dados foi utilizada para avaliar o comportamento das pessoas com relação ao descarte de medicamento, o nível de consciência sobre locais de descarte, recolhimento e campanhas públicas de divulgação.

A pesquisa foi aplicada na Faculdade de Paulínia e no Colégio Cosmos, situados na Rua Nelson Prodócimo, 495 - Bela Vista - Paulínia (SP), em sala de aula no período noturno, entre os dias 26 e 28 de outubro de 2011, com alunos dos diversos cursos de graduação e dos cursos técnicos, abrangendo um universo socioeconômico e cultural diverso da comunidade local.

Findo o prazo de aplicação das pesquisas, os dados coletados foram compilados em relatório único e feita a análise dos resultados.

Em paralelo foram realizadas visitas aos postos de saúde e farmácias da região, com a finalidade de obterem-se informações sobre a coleta e destinação final dos medicamentos descartados.

Fez parte também da proposta deste trabalho elaborar um cartaz explicativo, para ser afixado na Faculdade de Paulínia, que contemplasse informações sobre os impactos ambientais decorrentes do descarte inadequado de medicamentos e informações básicas de como proceder de forma correta.

\section{RESULTADOS E DISCUSSÕES}

A amostra abrangeu 613 alunos. Ficou evidenciado que 76\% dos entrevistados, o correspondente a 466 pessoas, residem na cidade de Paulínia, fato que direcionou para essa região a busca de informações adicionais para enriquecimento deste trabalho.

\section{Formas de descarte dos medicamentos vencidos}

A Figura 1 representa a distribuição das porcentagens referentes ao destino dado pelos alunos aos medicamentos vencidos.

Analisando-se a Figura 1 observa-se que, dentre os 613 entrevistados, a grande maioria faz o descarte dos medicamentos vencidos de sua residência de forma ambientalmente incorreta. Verifica-se que essa quantidade corresponde a $91 \%$ do total de entrevistados, somando-se a disposição efetuada no lixo comum, no reciclável e na água corrente, sendo que somente $4 \%$ destinam os medicamentos adequadamente em postos de saúde, farmácias ou centros comunitários.

\section{Média das quantidades descartadas de medicamentos sólidos e líquidos no período de um ano}

A Figura 2 demonstra as quantidades estimadas de medicamentos sólidos (expressas em comprimidos/ano) e líquidos (expressas em mL/ano) descartadas pelos entrevistados.

Quanto às quantidades descartadas conclui-se que a maioria dos entrevistados dispõe de pequena quantidade, sendo $55 \%$ até 4 comprimidos/ano e $13 \%$ até $50 \mathrm{~mL} /$ ano (Figura 2).

Embora esse resultado pareça insignificante, ao final de um ano, cerca de 1.300 comprimidos e aproximadamente 4 litros de fármacos são descartados no meio ambiente, considerando-se somente o âmbito desta pesquisa. Essa quantidade se torna expressiva se considerada a informação da ANVISA de que aproximadamente 28 mil toneladas de medicamentos são descartadas por ano no Brasil (ANVISA, 2011).

\section{Medicamentos descartados com maior frequência}

Na Figura 3 são observados os tipos de medicamentos mais descartados pelos alunos entrevistados.

Dentre os medicamentos votados elegem-se os antibióticos (39\%), analgésicos (33\%) e anti-inflamatórios (16\%) como predominantes (Figura 3).

Esses fármacos são considerados na atualidade como "poluentes orgânicos emergentes", bem como uma variedade de outros produtos comercializados que incluem, além de medicamentos, produtos de uso veterinário, de higiene, agrotóxicos, entre outros (SILVA; COLLINS, 2011).

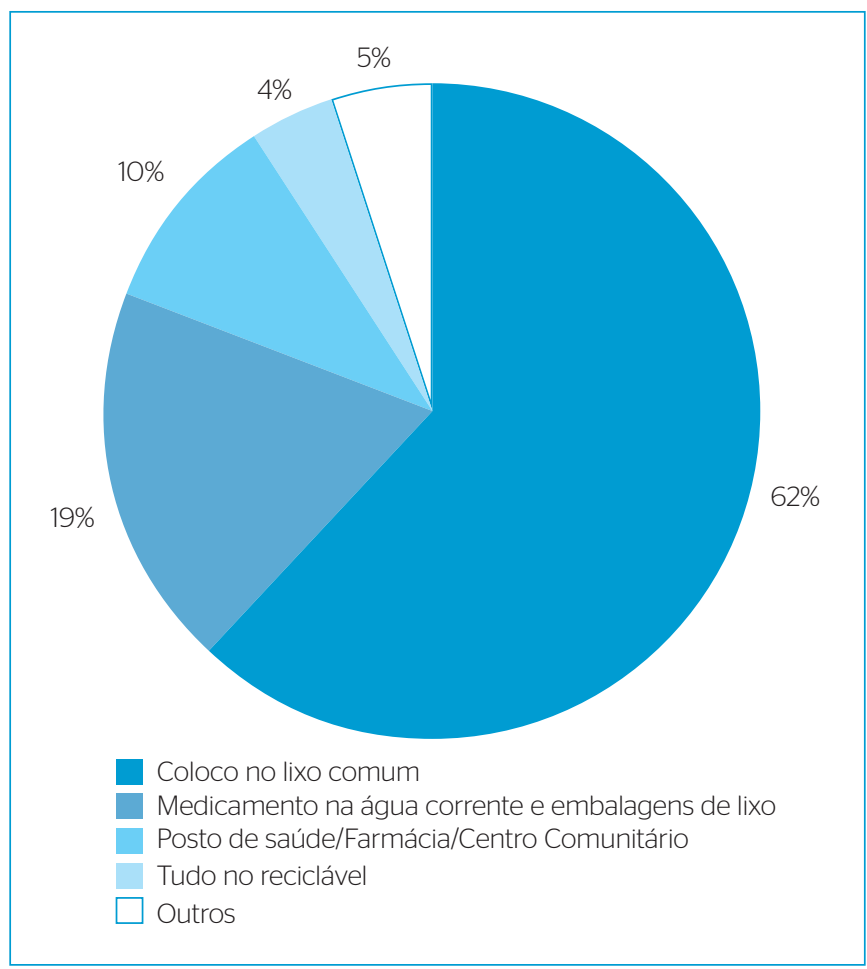

Figura 1 - Formas de descarte de medicamentos de residências. 
Esses poluentes podem ser encontrados disseminados no meio ambiente, mas não são usualmente monitorados, pois não possuem legislação regulatória correspondente, embora apresentem riscos ambientais e à saúde humana (SILVA; COLLINS, 2011).

De acordo com Bila e Dezotti (2003), o uso desenfreado de antibióticos pode acarretar problemas ambientais, como a contaminação dos recursos hídricos. Essas substâncias são frequentemente encontradas em efluentes de Estações de Tratamento de Esgoto (ETEs), e, por serem bastante persistentes, não são totalmente removidas durante os tratamentos convencionais de água (BILA; DEZOTTI, 2003).

Outro problema encontrado é que alguns micro-organismos criam resistência aos fármacos antibióticos. As bactérias fazem mudanças em seu material genético e adquirem resistência. Assim, uma bactéria presente em um rio que contenha traços de antibióticos pode tornar-se resistente a essa substância (BILA; DEZOTTI, 2003).

Conforme Carvalho et al. (2009), segundo pesquisa realizada nos Estados Unidos e publicada em 2008, cerca de 41 milhões de cidadãos americanos, em 24 áreas metropolitanas, recebem água potável contaminada por uma variedade de produtos farmacêuticos, como antibióticos, hormônios, entre outros.

Apesar da restrição na venda dos antibióticos, mediante receita médica controlada, essa substância ainda representa o maior índice

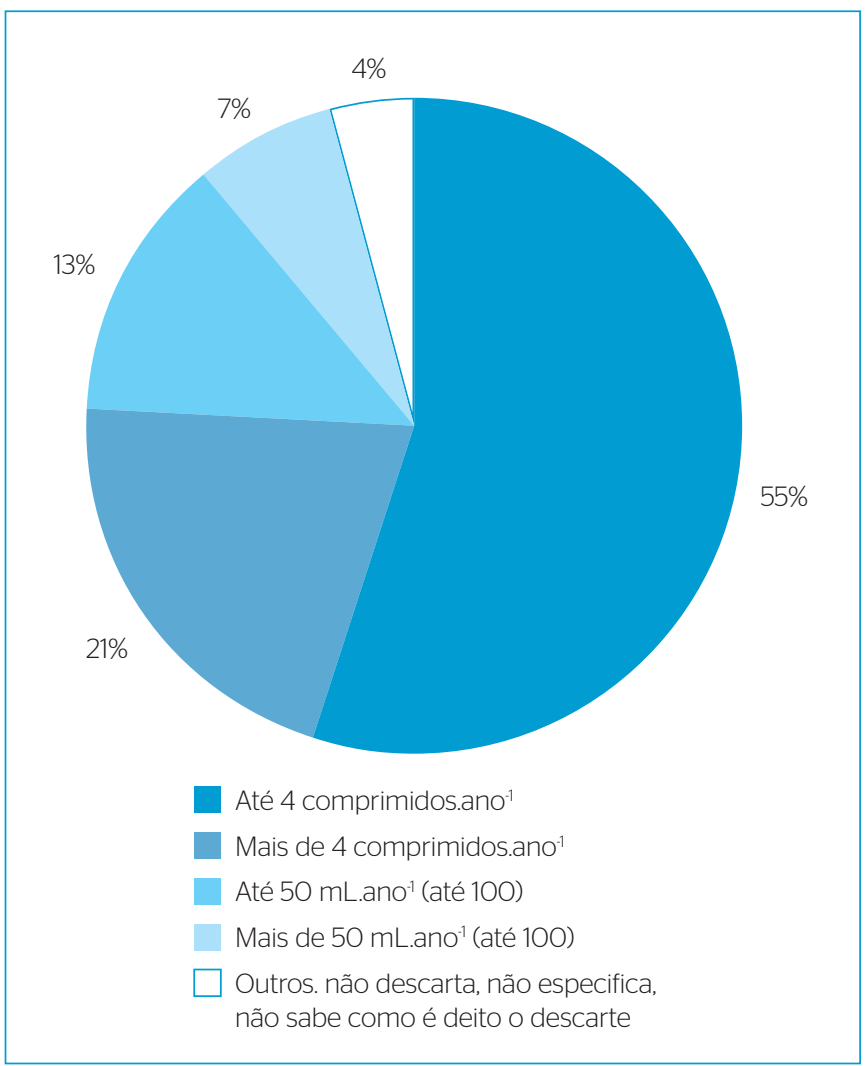

Figura 2 - Quantidade de medicamentos sólidos e líquidos descartados pelos entrevistados, no período de um ano. de descarte. Espera-se que, em médio e longo prazo, esse procedimento possa inibir a automedicação e que ocorra uma significativa redução na utilização desses fármacos e consequente diminuição do descarte.

\section{Conhecimento dos entrevistados sobre locais de recolhimento de medicamentos}

A Figura 4 resume a indicação do conhecimento dos entrevistados sobre locais adequados para descarte dos medicamentos vencidos.

A Figura 4 salienta que $92 \%$ dos entrevistados, totalizando 564 pessoas, não têm conhecimento dos locais de recolhimento dos medicamentos. Isso evidencia que as pessoas efetuam o descarte inadequadamente por falta de informação.

\section{Conhecimento de campanhas públicas indicadas pelos entrevistados da Faculdade de Paulínia}

A Figura 5 apresenta os percentuais de conhecimento dos entrevistados sobre a existência ou não de campanhas públicas de esclarecimento quanto ao descarte correto de medicamentos.

Pode-se observar na Figura 5 que 98\% dos entrevistados não tiveram a oportunidade de assistir, ler ou tomar conhecimento sobre campanha pública informativa alguma sobre o descarte de medicamentos.

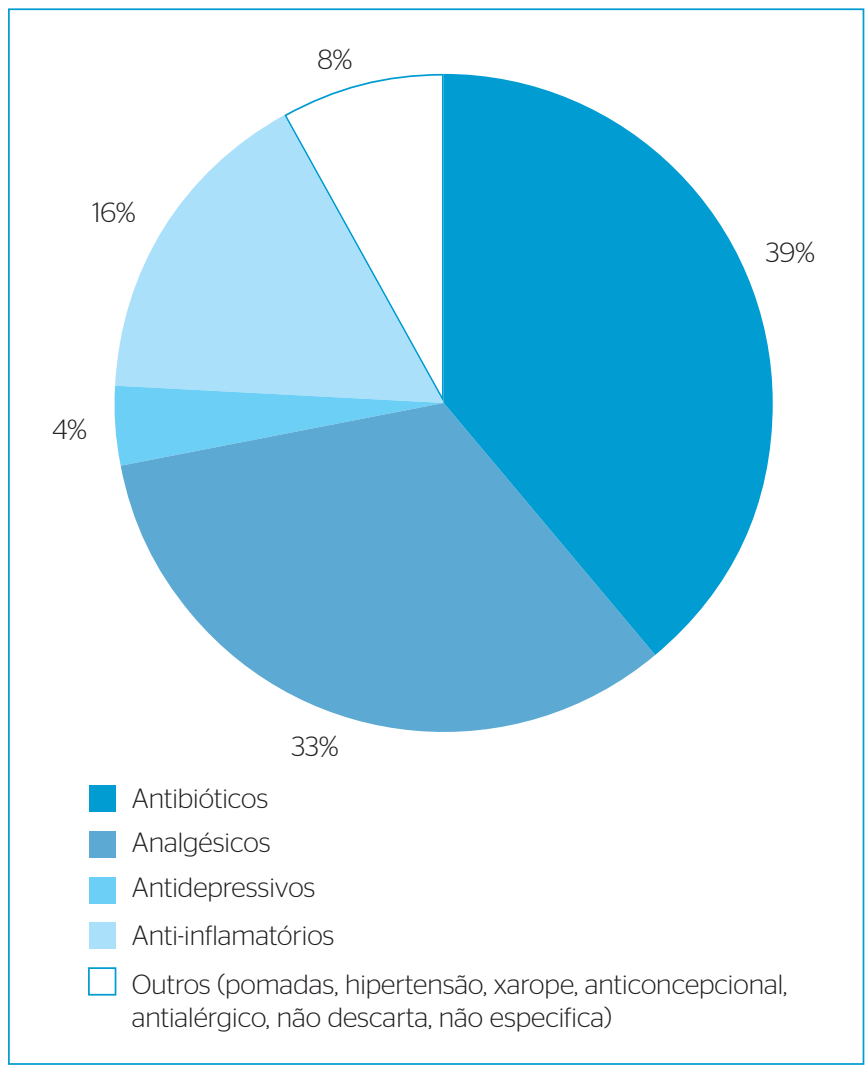

Figura 3 - Tipos predominantes de medicamentos vencidos descartados pelos entrevistados. 


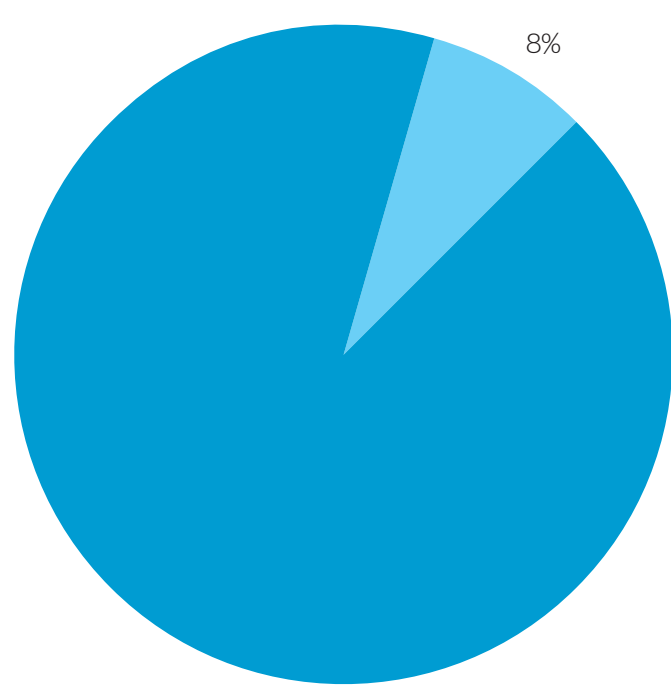

$92 \%$

Sim (posto de saúde, farmácia, vigilância sanitária, empresa onde trabalha)

Não

Figura 4 - Conhecimento dos entrevistados sobre locais de descarte de medicamentos vencidos.

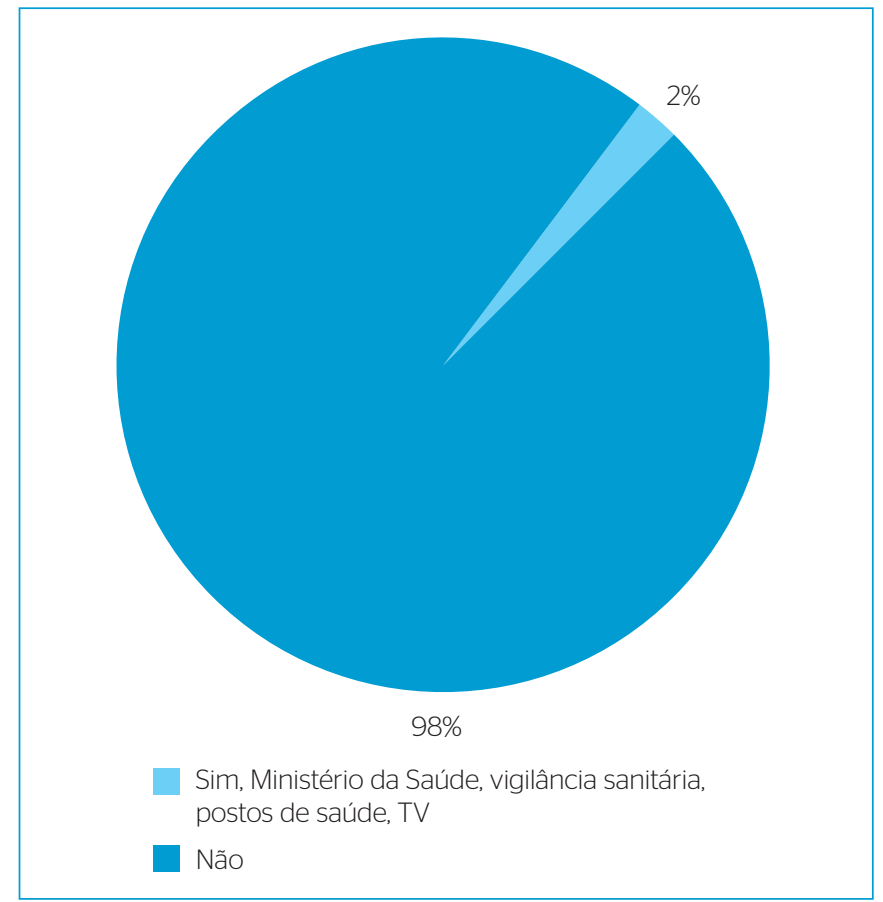

Figura 5 - Conhecimento de campanhas públicas sobre descarte de medicamentos vencidos de residências.

De acordo com informações da Vigilância Sanitária de Paulínia, a região possui oito postos de saúde para atendimento à população $\mathrm{e}$ todos recebem medicamentos vencidos.
A cidade possui aproximadamente 30 farmácias e 14 delas participaram da pesquisa, sendo que apenas 2 recebem os fármacos vencidos, ou seja, somente $7 \%$ disponibilizam esse serviço à população.

Na Columbia Britânica, a maioria das farmácias recolhe fármacos vencidos, prática esta que foi adotada pela Associação Nacional de Autoridades Regulatórias de Farmácia do Canadá (CRESTANA; SILVA, 2011).

Em visita aos postos de saúde, uma unidade de Paulínia (SP) e uma de Barão Geraldo- Campinas (SP) forneceram a informação que ambas recolhem medicamentos, não só vencidos como também aqueles que não têm mais utilidade para os pacientes.

Os fármacos vencidos são destinados à Vigilância Sanitária, que providencia a destinação final encaminhando-os para incineração.

Os medicamentos que ainda se encontram dentro do prazo de validade permanecem no posto de saúde para nova utilização.

Se o conhecimento dessas práticas estivesse ao alcance de todos, grande parte desses medicamentos deixaria de ir para o lixo, ou até mesmo para incineração.

\section{CONCLUSÃO}

Ficou evidenciada nesta pesquisa a falta de preocupação do poder público para investir em campanhas de promoção visando à conscientização da população no que tange ao descarte de medicamentos vencidos.

Quase a totalidade das pessoas pesquisadas não faz o descarte de forma adequada, não tem conhecimento sobre os locais de entrega e nem de campanhas ou propagandas públicas sobre os locais que recolham os medicamentos vencidos e restos.

Identifica-se a necessidade imediata, por parte do poder público, de se veicularem campanhas de esclarecimento, utilizando-se os principais meios de comunicação como o rádio, a internet e a TV, principalmente em horário nobre, a fim de maximizar o alcance do objetivo.

Importante observar que o descarte inadequado de medicamentos é de relevante impacto ambiental, fato este que também deve ser abordado nas campanhas públicas de esclarecimento, pois a sociedade de maneira geral desconhece as consequências que esse ato pode causar ao meio ambiente e também aos seres vivos.

A divulgação e a extensão da venda fracionada para um número maior de medicamentos também seriam um grande fator de redução desse descarte, além do desperdício, dado o custo de cada um desses medicamentos comparado a real acessibilidade da população brasileira a essas drogas.

A questão que inicialmente era apenas ambiental permeia pelos aspectos econômico e social em igualdade de importância. Ressalta-se que para alcançar a sustentabilidade ambiental deve-se também investir em pequenas campanhas de esclarecimento, mas que podem ter no final um alto resultado. 


\section{REFERÊNCIAS}

ANVISA - AGÊNCIA NACIONAL DE VIGILÂNCIA SANITÁRIA. Medicamentos. Descarte de Medicamentos: Responsabilidade Compartilhada. Disponível em: <http://pisast.saude.gov.br:8080/ descartemedicamentos/apresentacao-1>. Acesso em: 13 nov. 2011.

BILA, M.B. \& DEZOTTI, M. (2003). Fármacos no meio ambiente. Química Nova, v.. 26, n. 4, p. 523-530

BRASIL. (2004). MINISTÉRIO DA SAÚDE. Agência Nacional de Vigilância Sanitária. Resolução da Diretoria Colegiada - RDC n0 306, de 7 de dezembro de 2004. Disponível em: <http://cfo.org.br/wpcontent/uploads/2009/10/resolucao_rdc_306_ANVISA_2004.pdf>. Acesso em: 26 nov. 2011.

BRASIL. (2005). Resolução CONAMA no 358 de 29 de abril de 2005. Dispõe sobre o tratamento e a disposição final dos resíduos dos serviços de saúde e dá outras providências. Publicação DOU, n. 084, de 04 de maio de 2005, p. 63-65. Disponível em: <http://www.mma.gov. br/port/conama/legiabre.cfm?codlegi=462>. Acesso em: 26 nov. 2011.

BRASIL. (2010). Lei no 12305, de O2 de agosto de 2010, institui a Política nacional de Resíduos Sólidos. Disponível em: <http://www.planalto.gov. br/ccivil_03/_ato2007-2010/2010/lei//12305.htm>. Acesso em: 13 nov. 2011.

BRASIL. (2011). Projeto de Lei no 595/2011. Ementa: Acrescenta o art. 6-A à Lei no 5.991 de 17 de dezembro de 1973, para dispor sobre o recolhimento e o descarte consciente de medicamentos. Disponível em: <http://www.camara.gov.br/proposicoesWeb/fichadetramitacao?id Proposicao=493432>. Acesso em: 13 nov. 2013.

BUENO, C.S.; WEBER, D.; OLIVEIRA, K.R. (2009). Farmácia Caseira e Descarte de Medicamentos no Bairro Luiz Fogliatto do Município de ljuí - RS. Revista de Ciências Farmacêuticas Básica e Aplicada, v. 30, n. 2, p. 75-82.

CARNEIRO, F. Descartar medicamentos vencidos ainda é problema. São Paulo: Universidade Metodista de São Paulo. Disponível em: <http://www.metodista.br/rronline/rrjornal/2011/ed.970/descartarmedicamentos-vencidos-ainda-e-problema>. Acesso em: 26 nov. 2011.
CARVALHO, E.V.; FERREIRA, E.; MUCINI, L.; SANTOS, C. (2009). Aspectos Legais e Toxicológicos do Descarte de Medicamentos. Revista Brasileira de Toxicologia, v. 22, n. 1-2, p. 1-8.

CRESTANA, G.B. \& SILVA, J.H. (2011). Fármacos residuais: panorama de um cenário negligenciado. Revista Internacional de Direito e Cidadania, n. 9, p. 55-65.

EICKHOFF, P.; HEINECK, I.; SEIXAS, L.J. (2009). Gerenciamento e destinação final de medicamentos: uma discussão sobre o problema. Revista Brasileira de Farmácia, v. 90, n. 1, p. 64-68.

GUIMARÃES, G.L. Impactos ecológicos do uso de herbicidas ao meio ambiente. (1987). Série Técnica IPEF, v. 4, n. 12, p.159-180.

LIBRELON, R. Venda fracionada de medicamentos pode ser obrigatória Agência Câmara de Notícias. Disponível em: <http://www2.camaraleg br/camaranoticias/noticias/SAUDE/200153-VENDA-FRACIONADA-DEMEDICAMENTOS-PODE-SER-OBRIGATORIA.html>. AcesSo em: 26 nov. 2011

MORAIS, I. Descarte de Medicamentos Preocupa Especialistas. São Paulo: Revista Espaço Aberto USP. Disponível em: <http://espaber. uspnet.usp.br/espaber/?materia=descarte-de-remedios-preocupaespecialistas>. Acesso em: 19 nov. 2011.

RODRIGUES, C.R.B. (2009). Aspectos legais e ambientais do descarte de resíduos de medicamentos. 2009. 110 f. Dissertação (Mestrado em Engenharia de Produção). Universidade Tecnológica Federal do Paraná, Ponta Grossa.

SILVA, C.G.A. \& COLLINS, C.H. (2011). Aplicações de Cromatografia Líquida de Alta Eficiência para o Estudo de Poluentes Orgânicos Emergentes. Química Nova, v. 34, n. 4, p. 665-676.

UEDA, J.; TAVERNARO, R.; MAROSTEGA, V:; PAVAN, W. (2009). Impacto Ambiental do descarte de fármacos e estudo da conscientização da população a respeito do problema. Revista Ciências do Ambiente (on-line), v. 5, n. 1. Disponível em: <www2.ib.unicamp.br/revista/be310/index.php/ be310/article/viewFile/176/129>. Acesso em: 13 nov. 2011. 